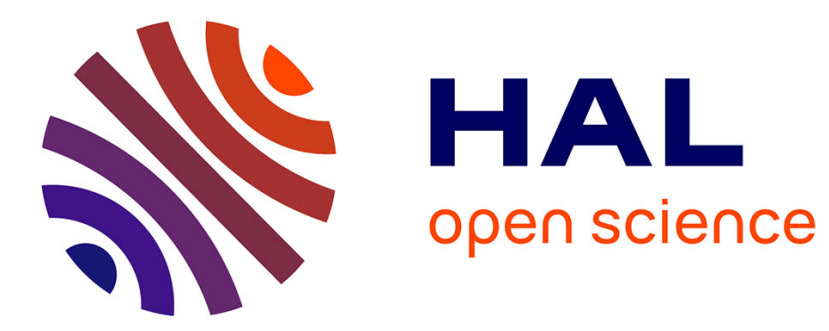

\title{
Metaphors in Nanomedicine: The Case of Targeted Drug Delivery
}

Bernadette Bensaude-Vincent, Sacha Loeve

\section{To cite this version:}

Bernadette Bensaude-Vincent, Sacha Loeve. Metaphors in Nanomedicine: The Case of Targeted Drug Delivery. NanoEthics, 2014, 8 (1), pp.1 - 17. 10.1007/s11569-013-0183-5 . halshs-01076477

\section{HAL Id: halshs-01076477 https://shs.hal.science/halshs-01076477}

Submitted on 22 Oct 2014

HAL is a multi-disciplinary open access archive for the deposit and dissemination of scientific research documents, whether they are published or not. The documents may come from teaching and research institutions in France or abroad, or from public or private research centers.
L'archive ouverte pluridisciplinaire HAL, est destinée au dépôt et à la diffusion de documents scientifiques de niveau recherche, publiés ou non, émanant des établissements d'enseignement et de recherche français ou étrangers, des laboratoires publics ou privés. 


\title{
Metaphors in Nanomedicine: The Case of Targeted Drug Delivery
}

\author{
Bernadette Bensaude Vincent, Cetcopra, Université Paris 1 \& IUF \\ bensaudevincent@gmail.com \\ Sacha Loeve, Cetcopra, Université Paris 1 \\ sacha.loeve@univ-paris1.fr
}

\begin{abstract}
The promises of nanotechnology have been framed by a variety of metaphors, that not only channel the attention of the public, orient the questions asked by researchers, and convey epistemic choices closely linked to ethical preferences. In particular, the image of the 'therapeutic missile' commonly used to present targeted drug delivery devices emphasizes precision, control, surveillance and efficiency. Such values are highly praised in the current context of crisis of pharmaceutical innovation where military metaphors foster a general mobilization of resources from multiple fields of cutting-edge research. The missile metaphor, reminiscent of Paul Ehrlich's 'magic bullet', has framed the problem in simple terms: how to deliver the right dose in the right place at the right moment? Chemists, physicists and engineers who design multi-functional devices operating in vitro can think in such terms, as long as the devices are not actually operating through the messy environment of the body. A close look at what has been done and what remains to be done suggests that the metaphor of the "therapeutic missile" is neither sufficient, nor even necessary. Recent developments in nanomedicine suggest that therapeutic efficacy cannot be obtained without negotiating with the biological milieu and taking advantage of what it affords. An 'oïkological' approach seems more appropriate, more heuristic and more promising than the popular missile. It is based on the view of organism as an oikos that has to be carefully managed. The dispositions of nanocapsules have to be coupled with the affordances of the environment. As it requires dealing with nanoparticles as relational entities (defined by their potential for interactions) rather than as stable substances (defined by intrinsic properties) this metaphor eventually might well change research priorities in nanotechnology in general.
\end{abstract}

KEY WORDS: nanomedicine; pharmacology; nanorobot; magic bullet; dispositions; affordances; efficiency; efficacy. 


\section{Metaphors in Nanomedicine: The Case of Targeted Drug Delivery}

\section{Introduction}

The use of nanoparticles for delivering drugs on a specific site is one of the most attractive promises of nanotechnology today. Targeted drug delivery systems are nanostructures tailored to deliver pharmaco-active molecules just where it is needed (Manish and Vimukta, 2011, p. 135). The major advantage of drug vectorization is that it reduces the systemic toxicity of the medicine, thus minimizing side effects while improving its efficacy (Drews, 2000). In addition, this technique allows treating body parts that were once out of reach from most medicines (e.g.: the brain). Finally, the innovation is also sought for 'rescuing' or 'repurposing' drugs that were shelved for being too toxic.

Targeted drug delivery systems are flagship products of nanotechnology. Being less controversial than military applications of nanotechnology, such "nano-weapons" encourage public acceptance of nanotechnology. Reminiscent of the popular image of the 'magic bullet', current research projects in nanotechnology for drug delivery are pervaded by a host of warfare metaphors such as 'therapeutic missiles', 'nano bullets', 'nano-weapons', 'smart bombs', 'stealth kill', and 'targeted strike' without 'collateral damages' (Gabizon, 2001; Bhattacharya, 2003; Harney 2004; Patel 2007; Perez, 2008; Kain, 2008; Choi, 2009; Henderson 2009; Singer 2009; Rai et al. 2012; Rossi 2012). Such metaphors used in popular journals and scientific publications have shaped the conceptual structure of the research field.

To be sure, this is not specific to nanomedicine. Warfare metaphors have pervaded medicine and healthcare for a very long time (Montgomery, 1991; 1996; Annas, 1995; Arrigo, 1999). Their use has been reinforced by the 'War on Cancer', launched by Richard Nixon in the 1970s. Focusing on the role of metaphors in nanomedicine, this paper pursues previous reflections on the uses and abuses of such metaphors (Nordmann, 2004; Nerlich, 2012). However, it goes further in claiming that the values underlying the dominant metaphoric framework are not sustainable enough to design nano-artefacts operating in a complex biological milieu.

Following a brief presentation of metaphors as conceptual tools, we contextualize the use of the missile metaphor against the background of the current pharmaceutical innovation crisis in relation to the history of pharmaceutical doctrines. Taking a closer look at the devices that have been designed over the past decades and at current research trends in this field we then argue that the missile or bullet metaphor provides a simplistic view of the complex technological systems required to achieve therapeutic efficacy. The military metaphor may suffice for chemists, physicists and engineers who design multi-functional devices operating 
in vitro, as long as they do not operate in the complex and messy environment of a diseased body. But actions and reactions of biological milieu must be integrated into the operational scheme of therapeutic devices. To go beyond efficiency and achieve therapeutic efficacy in vivo, nanodevices have to be designed not only as destructive weapons but as protective shells as well as secret agents conducting negotiations; the biological environment should be conceived as a dense milieu populated with multiple and heterogeneous actors rather than as an abstract space traversed by a moving body. Finally, we argue that the use of alternative 'oïkological' metaphors encapsulating not just the dispositions of the nano-object but also the affordances of the milieu may be useful to improve the technique. This requires dealing with nanoparticles as entities defined by their relations rather than as stable physical or chemical substances thereby calling for a redefinition of research priorities.

This claim is based on a number of research papers dealing with targeted drug delivery both in standard scientific journals and pharmaceutical research journals. Our review of literature has been guided and completed by oral interviews and extensive discussions with three scientists working specifically research field. ${ }^{1}$

\section{The Performances of Metaphors}

It is less a matter of questionning the performances of the therapeutic applications of nanotechnology than addressing the relevance of metaphors used in the design of nanovectors. However, it is not a mere clarification of words, disregarding concepts, material practices and ethical choices. Richard Rorty claims: 'It is pictures rather than propositions, metaphors rather than statements, which determine most of our philosophical convictions' (Rorty, 1979, p. 12). ${ }^{2}$ Metaphors defined as acts of 'understanding and experiencing one kind of thing in terms of another', are ordinary cognitive phenomena rather than mere stylistic devices (Lakoff and Johnson, 1980, p. 5). As the source domain shapes the 'target domain', metaphors allow grasping and shaping hitherto-unstructured or not-easily-accessible realities. Metaphors matter. They are powerful 'catalysts' in the dynamics of knowledge; they provide insights and generate new meanings and knowledge (Maassen and Weingart, 2000).

Metaphors are also vehicles for the transmission of meaning and values. Like viruses, they contaminate and colonise our minds regardless of well-established boundaries such as science versus society. George Lakoff and Mark Johnson emphasize that war metaphors are ubiquitous in the practices of arguing (we 'defend' or 'attack', 'gain' or 'lose', 'demolish'). They argue that not just our words, but our common world would be quite different had 'dance' been, for instance, the source domain of metaphors (1980, pp. 4-5). Metaphors do literally change the world. They belong to the realm of what John L. Austin called 'performative utterances' (Austin, 1962). They are 'performative' and not 'constative'. More than describing reality, they inform and transform it.

Scientific language is not deprived of performativity. Metaphors proliferate in the language of science for the purpose of communicating science to lay audiences, and they also circulate inside scientific communities. Evelyn Fox Keller's works outline the heuristic power of metaphors in biology (Fox Keller, 1992; 1995; 2002). 'Different metaphors of mind, nature, and the relation between them, reflect different psychological stances of observer to observed; these, in turn, give rise to different cognitive perspectives-to different aims,

\footnotetext{
${ }^{1}$ Interviews with Patrick Couvreur (Institut Galien Université Paris-Sud), Florence Gazeau (Laboratoire matière et systèmes complexes, Université Paris Diderot) and Ania Servant (Nanomedicine Laboratory, University College London School of Pharmacy).

${ }^{2}$ In Rorty's pragmatic philosophy, language is 'image-schematic' but it is not a representational 'mirror of nature': it is 'formative', i.e.: giving instructions to others about to give form to something, and per-formative, i.e.: being 'instructive' in that sense.
} 
questions, and even to different methodological and explanatory preferences' (1992, p. 30). She insists that "metaphors do far more than affect our perception of the world. They draw the attention of researchers, guide their activities and material manipulations' (2002, p. 290). In technology, metaphors can even be turned into operational analogies that make things work and help superseding obstacles.

What is exactly the descriptive power of the therapeutic missile metaphor (its adequacy) in nanomedicine? What about its prescriptive potential: does it shape research practices in this field? This metaphor suggests that new therapeutics can be framed along the model of ballistics. The objective is to carry and deliver the drug onto a target in order to optimize its 'launching window'. Precision guidance, efficiency without 'collateral damages', ... the advantages of nanovectors are listed in terms similar to those used to describe the performances of missiles or drones in modern warfare. Remarkably, the source domain in turn makes an extensive use of medical analogies such as 'surgical strikes', a metaphor used in warfare strategy and communication during the First Gulf War. No matter whether you want to heal people or kill them, no matter whether your action is good or bad, the ultimate values are control and precision.

\section{The magic bullet in the context of crisis of pharmaceutical innovation}

The hype surrounding nanotechnology and the claims that it brings about a revolution in medicine and pharmacy are based on the awareness of the limitations of current trends in pharmaceutical research. The frantic quest for the miracle molecule that would cure all cancers following Richard Nixon's launch of the 'War on Cancer' in 1971 ended in failure. It is now widely accepted that the 'blockbuster model' is inadequate. Cost soars and the rise of generic drugs are putting an increasing pressure on big pharmas as their amount of R\&D time and expenditures rise while the output of new therapeutic molecules decreases (DiMasi et al., 2003; Munos, 2009; Swinney and Anthony, 2011). Many products that are tested in clinical trials fail despite tremendous time investments —up to 15 years — and resource spendings. So hard is the 'Valley of Death' for candidate molecules before reaching the market that selective reporting of trials is a temptation for pharmaceutical companies (De Angelis et al., 2004; Goldacre, 2012).

In the face of this crisis, genomics, genetic engineering, nanotechnology and synthetic biology are expected to reinvigorate a decaying business model (Crawford, 2004; Paul et al. 2010). Both personalized medicine and targeted drug delivery attract big investments from the private and the public sectors concerned with the sustainability of the public health system (Downing 2009). They search for more 'rational' (based on molecular features) and more 'reasonable' (more profit and increased efficacy) ways of designing pharmaceutical products through more individualized administration of drugs. While in personalized medicine better administration means better prescription, ${ }^{3}$ in drug targeting it translates as better delivery. Personalized medicine and target drug delivery are seen as complementary rather than competing strategies (Jain, 2005; Morris, 2012). ${ }^{4}$ By adjusting prescription and delivery to

\footnotetext{
${ }^{3}$ Because all individuals are not responding to the same drug, personalized medicine is looking for molecular signatures - so called 'biomarkers' - that would allow to direct different categories of patients to more adapted therapies, possibly on the basis of early diagnoses (molecular biomarkers are anything that can be detected and used for measuring the probability of incidence of a disease, its progress, or its treatment's effects: DNA or RNA single nucleotide polymorphism, protein, complex of proteins, or changes in protein expression).

${ }^{4}$ Personalized medicine seeks to specify therapy by means of profiling and stratification: It sets up distinct categories of patients with regard to their probability of better responding to this or that therapy on the basis of tests determining the presence of a biomarker. It is to form categories of patients fitting with prescriptions and conversely to adjust prescriptions to categories of patients. Targeted drug delivery, by contrast, starts from a
} 
individual profiles, well-established medicines may be used to better effect (Chess, 1998). It is a key argument for stimulating public adhesion because it seems to overcome the disadvantages and defects of conventional therapeutics. Both sectors have raised intense mobilization over the past decade as a result of a remarkable convergence of interests between patients, science, politics and business. Patients and physicians want to avoid the damages caused by conventional chemotherapy and radiotherapy in the treatment of cancers. Pharmaceutical companies want to avoid the rising research costs for new therapeutic molecules, and public health services want to avoid the tremendous financial loss due to the inefficacy of a large proportion of medical prescriptions. Although big pharmaceutical companies are still hesitant to invest in this field ${ }^{5}$, they see targeted drug delivery as an opportunity to renew their patent portfolios ${ }^{6}$. On the business side, drug targeting is expected to cover $75 \%$ of the nanomedicine market (Wagner et al., 2006). Therefore hundreds of research laboratories across the globe are currently bringing together the resources from nanotechnology, advanced polymer and lipid chemistry, physics and molecular biology in order to find new ways of vectorizing drugs. Such is the pressure for introducing this new technique in cancer therapeutics that hundreds of candidate products are now in clinical trials. It is reported that 27 candidate products have already been approved by the US Food \& Drug Administration in 2012 (Observatory NANO, 2012). Targeted drug delivery has become a target in itself justifying a warlike mobilization, reinforced by a rhetorical arsenal of 'therapeutic missile', 'smart bombs', and the like. As the military metaphors inspire a convergence of efforts on a common target designated as the enemy, they are self-vindicating. In using them, nanotechnologists, physicians, and patients struggling against cancer may feel that they participate in a general mobilisation for an intrinsically good cause (Nerlich, 2012).

\section{The magic bullet and the two cultures of pharmacology}

The climate of crisis in pharmaceutical innovation may have intensified the use of warfare metaphors but the metaphors have been around in the twentieth century. Their success testifies to the triumph of the chemical approach to medicine, initiated by Paracelsus in the sixteenth century against the older Galenic tradition ${ }^{7}$. Paracelsus grounded his therapeutic approach on a theory of secrete correspondences or sympathies between each of the seven metals known in his time and the specific parts of the human body (Debus 1991; Debus 1993). He assumed that disease was caused by external foreign agents acting as poisons on a specific area of the body. Diseases were viewed as localized physical things that the physician sought to eradicate from the body with the help of an appropriate chemical substance. By contrast, the Galenic tradition emphasized the role of fluids and viewed disease as the result of disturbance in the balance of fluids due to an excess of one of the four basic humours. The

given molecule and a given target (organ, tissue, cell, organelle or molecular receptor) and seeks the most fitting nanoscale formulation to carry the molecule to the target.

${ }^{5}$ Currently, the innovation landscape of nanovectorization is mostly populated with small start-ups selling their patents to big pharmaceutical companies. (Observatory NANO 2010). They rely on venture capitals and business angels to bear the costs of preclinical development, scaling-up studies, upgrading to legal standards, and phase-I to mid-phase-II trials. Big pharmas cover only end-phase-II and phase III. They adopt a 'wait-and-see' strategy (te Kulve \& Rip 2013: 4) and refuse to rush head down towards a disruptive technology unless it has pugnaciously proven its safety and efficiency (Couvreur 2010b).

${ }^{6}$ It is expected that targeted drug delivery will provide pharmaceutical industry with new patents thanks to the nanoformulation of established molecules before the end period of their IP rights. It also allows patenting older medicines that so far could not enter the market (Bawa, 2008; te Kulve \& Rip 2013: 3).

${ }^{7}$ Here we take the two rival founding fathers as mythical figures. It matters little to us whether Galen and Paracelsus were really what their heirs have made of them. The master narrative built on the two heroes are still framing pharmacological culture. 
role of the physician was to restore what we call today the body's homeostasis by prescribing the opposite humour. While Galenic medicine dealt with the organism as a whole and a nexus of relations, Paracelsian therapeutics rests on the affinity of chemicals with specific tissues. The holistic concept of disease characteristic of the Galenic tradition has been overthrown by an ontological concept of disease as an ens morbi, a material and localized entity.

The idea of eradicating disease with an appropriate molecule came out of advances in synthetic chemistry and stereochemistry at the turn of the twentieth century (Pillai et al., 2008). Paul Ehrlich, in particular, paved the way to targeted medicine. As a 'microbe hunter', he was one of the first scientists to use staining techniques to detect particular cells. While studying the selective action of aniline dyes on biological tissues, he hypothesized that cells have specific receptors enabling them to take up specific molecules. Just as Emil Fischer had ventured the analogy between lock and key to explain how enzymes bind with specific substrates, Ehrlich used the hypothesis of chemical affinities - called today 'mechanisms of molecular recognition' - to identify toxins with a selective therapeutic action on specific cells. He thus tested hundreds of dyes on mice in search for the unique dye that could target the large trypanosome responsible for sleeping sickness. In 1910, he obtained an effective drug against syphilis, Salvarsan. Based on the molecular recognition between toxin and tissue, his strategy inspired the image of 'magic bullet', chosen as the title for a 1940 biographical movie, Dr Ehrlich's Magic Bullet (Fig.1). ${ }^{8}$

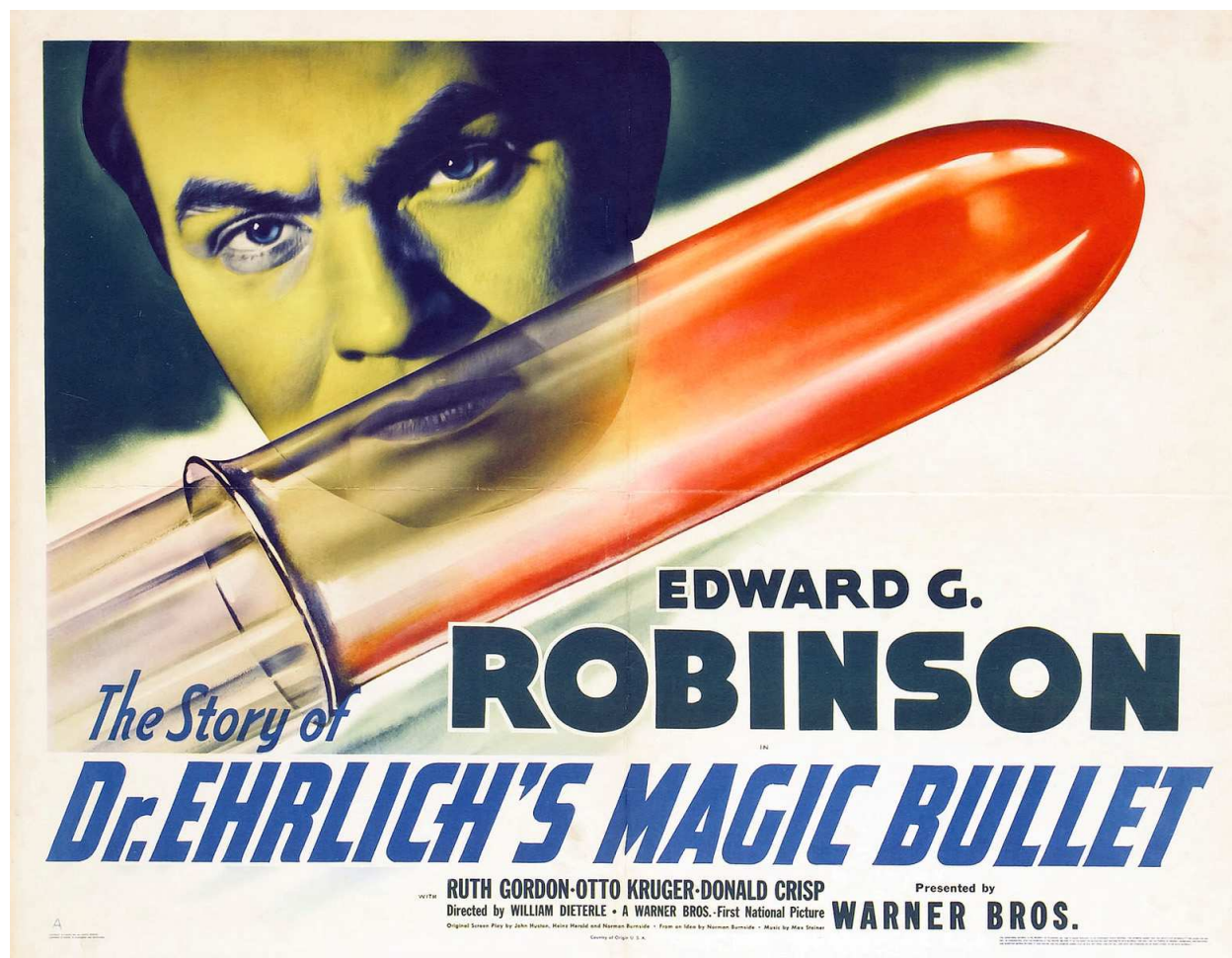

Fig. 1. Dr Ehrlich's Magic Bullet, 1940, original motion picture poster, () 1940 Warner Bros.

\footnotetext{
${ }^{8}$ Ehrlich wrote that "If we picture an organism as infected by a certain species of bacterium, it will obviously be easy to effect a cure if substances have been discovered which have an exclusive affinity for these bacteria and act deleteriously or lethally on these alone, while at the same time they possess no affinity for the normal constituents of the body and can therefore have the least harmful, or other effect on that body. Such substances would then be able to exert their full action exclusively on the parasite harboured within the organism and would represent, so to speak, magic bullets, which seek their target of their own accord" (Ehrlich [1906] 1960, p. viii).
} 
So appealing was this popular image that it has been taken up by drug designers and gradually became a kind of ideal-type driving research efforts (Strebhardt and Ullrich, 2008). The 'magic bullet' model underlies many research strategies that came to prevail in twentiethcentury pharmaceutical industry. New techniques invented in the 1960 s reinforced the Paracelsian concept of disease as a local target to shoot. When systems of controlled drugdelivery came into use for a number of diseases (Hoffman, 2008), the 'magic bullet' became a fashionable motto. The metaphor almost turned into a real thing in the 1970s as pharmaceutical companies began producing monoclonal antibodies by cloning a unique parent cell having some specific action on tumours. It became even more prevalent with the proofs of concept of 'microspheres' (Kramer, 1974), 'Nanokapsul' (Kopf, 1975), and 'Nanopartikel' (Kopf et al., 1976) that penetrate into specific cells for drug, gene or protein delivery, due to Peter Speiser and his team at ETH Zürich (Couvreur et al., 1977; Kopf et al., 1977; Marty, 1977; Marty et al., 1978). The 'magic bullet' is now integrated in more complex systems aimed at materializing the ideal-type of targeted therapeutics. The expectation is to shift from the painstaking drug screening - testing lots of molecules on all possible targetsto the direct design of the unique weapon adjusted to its target.

The pharmaceutical arsenal enriched with such magic bullets is clearly an outcome of the Paracelsian tradition. To what extent does it mark the death of the Galenic approach to diseases? Could targeted drug delivery be alternatively viewed as a revenge of Galenics, as it has been suggested by Patrick Couvreur, a Belgian scientist who pioneered the field of targeted drug delivery? (Couvreur, 2009) Surely, drug delivery just like today's Galenic pharmacology is concerned with the formulation and administration of drugs. ${ }^{9}$ The delivered substance matters less than the mode of delivery. All efforts are thus aimed at designing new medicinal forms (Galenic forms) rather than new drugs. The goal is less to increase the efficiency of the therapeutic agent than to enhance the therapeutic index (the toxic vs. therapeutic dose ratio) by increasing the efficacy of delivery.

Are we to assume that targeted drug delivery may be seen as a reconciliation of the two alternative conceptions of disease and therapeutics? To address this question, it is necessary to characterize the material practices of design.

\section{Engineering therapeutic devices}

Current research on targeted drug delivery differs in substantial ways from both traditions in that it turns therapeutics into engineering. Indeed, like all therapeutic traditions, targeted drug delivery is mainly concerned with maximizing the efficacy of treatment and reducing harm. As such, however, therapeutics is conceptualized as an engineering problem that can be anatomized in unit operations.

The technique is divided up in three basic unit operations: loading, addressing, and releasing the active therapeutic molecule, each operation having specific design requirements. This sequence of operations could apply to the preparation of a missile, and the therapeutic action is conceived in terms similar to any ballistic problem.

The first operation-loading (Fig. 2)-requires the design of a vehicle (capsule, sphere, micelle, dendrite, shell...) 'to carry the drug in a controlled manner from the site of

\footnotetext{
${ }^{9}$ Significantly, twentieth century Galenics refers to the 'formulation' of drugs, i.e.: making tablets, suppositories, creams or syrups, according to a specific procedure called a 'formula' (a medicinal form suitable for administration). Galenics is often despised by modern pharmacology as being concerned with external form or packaging instead of active principles, as being technique or even marketing, not science-a rather unfair view, since it is Galenics that allows the transformation of a mere 'drug' into a proper 'medicine'. Galenic pharmacy is indeed indispensable for the standardisation of doses and posology as well as for the stabilisation and conservation of active substances (Rasmussen, 2005). Galenics is the art of taming substances.
} 
administration to its therapeutic target' (Couvreur, Vauthier, 2006: 1417). Since the first capsules synthesized in the 1970s with polyacrylamide, polyalkylcyanoacrylate, albumin, or micelles, numerous candidate materials-polymers, liposomes, cyclodextrins and other nanoparticles- have been tested as drug vehicles.

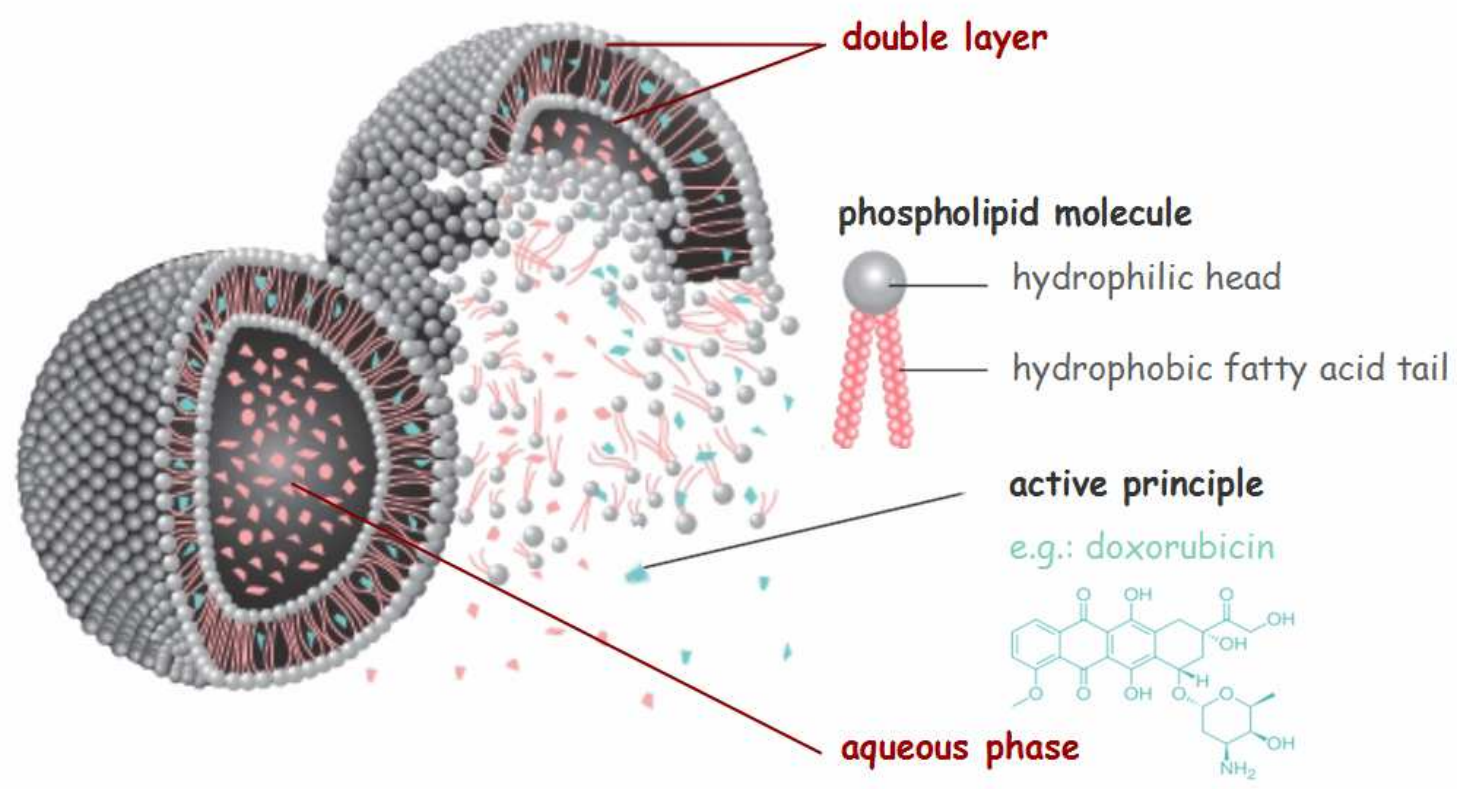

Fig. 2. Encapsulation of a drug in a liposome (S. Loeve, original picture).

There are some specific requirements for the design of a nanocarrier: size (it must not be too big, not too small in order to selectively cross barriers); encapsulation rate (it must take up a reasonable amount of therapeutic molecules while polymerizing ${ }^{10}$ ); stability (it must resist bio-erosion); biocompatibility (solubility and avoidance of unwanted accumulation) and biodegradability once the capsule's mission is completed.

Addressing the drug by controlling the movements of the carrier along its trajectory is the core of the targeting strategy. Ballistic metaphors flourish to describe the battery of techniques that have been developed. Although 'vectorization' does not explicitly convey a military image, it connotes the trajectory of a mobile through a geometrical space, which is the key concept of ballistics. The frequent use of the arrow symbol in the iconography of nanovectors reminiscent of the Euclidian vectors used in classical physics reinforces the ballistic connotation. In addition, fighter aircrafts are often referred to as 'vectors' in the control rooms of military operations. In the case of functionalized nanocarriers with receptorspecific ligands, the ballistic metaphor of the 'missile' or 'vector' is often supplemented with the cybernetic metaphor of the 'homing device' 11 , thereby converting the old ballistic metaphors into modern (informational) warfare and 'smart' weapons. To cap it all, theranostic nanoplatforms guided by ultrasounds or magnetic fields are designed as kinds of drones: their destructive payload can be remotely triggered while their localization can be tracked on a screen. Nanovectors rhyme with Terminators (i.e, robots programmed to kill and to never miss their target). The so-called 'third-generation nanovectors' (Couvreur and Vauthier 2006)

\footnotetext{
${ }^{10}$ The encapsulation rate is one of the major bottlenecks for the technique. Currently, most systems do not exceed a rate of $10 \%$ of active principles encapsulated on the total amount of nanoparticles synthesized, which limits both their cost-efficiency and therapeutic index.

${ }^{11}$ Actually, Norbert Wiener's conceptualization of feedback or retroaction originated in his warfare research on self-guided devices during World War II (Galison 1994).
} 
are designed for 'active targeting' thanks to their 'decoration' with 'molecular probes' (antibodies or ligands) devised to recognise the target's specific receptors (Fig.3). These specific ligands grafted on the carrier's coating are often dubbed 'homing devices'. They can also feature cell-penetrating peptides or intracellular adhesion molecules to facilitate the intracellular penetration of the vector (Hillaireau and Couvreur, 2009).

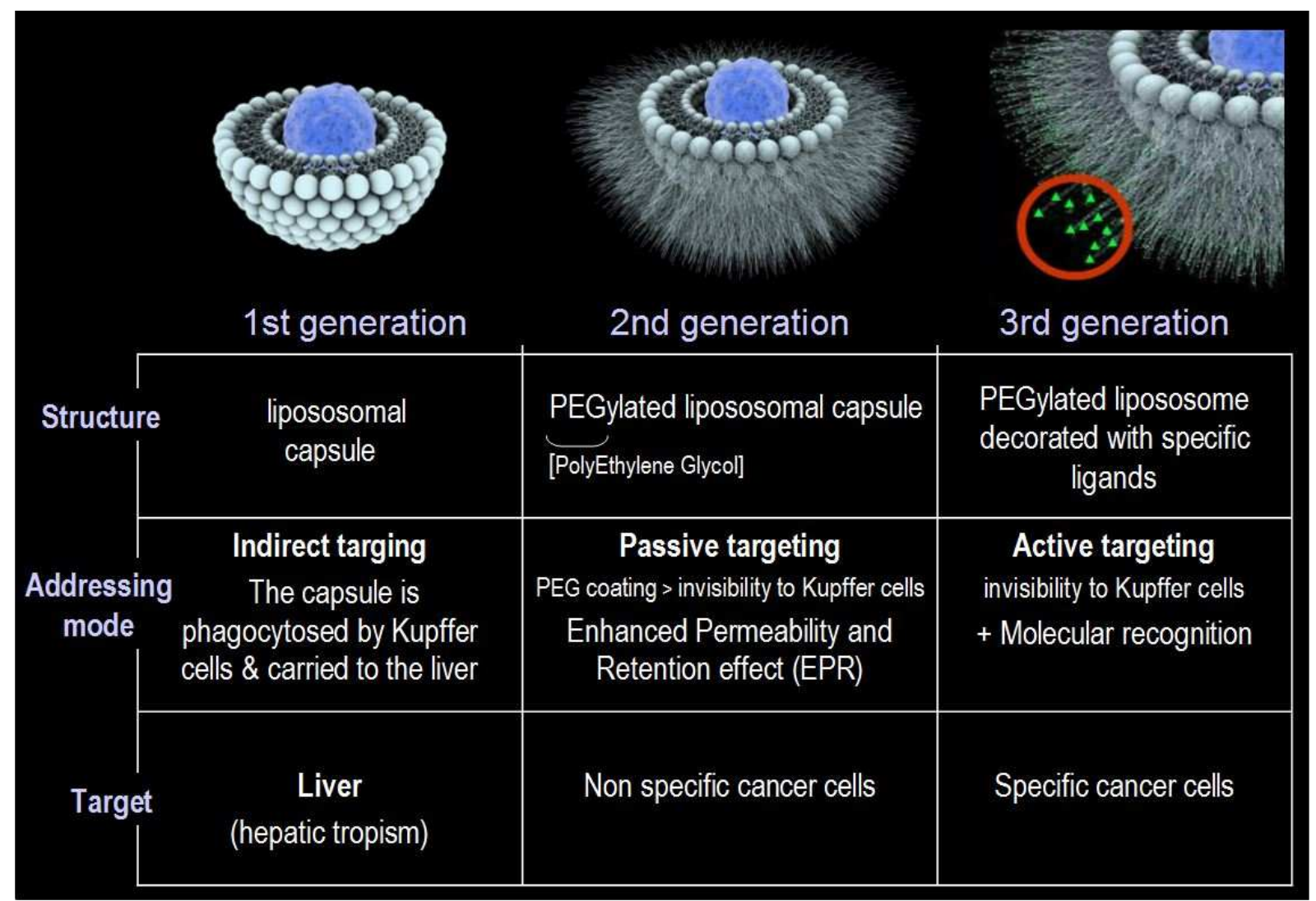

Fig. 3. Three generations of nanovectors according to Couvreur and Vauthier (2006). (S. Loeve, original picture).

In addition to chemical means of targeting, active targeting can also be obtained by using physical stimuli such as X-rays, infrared, ultrasounds, or magnetic field providing guidance (with magnetite embedded in the carrier). Embedded magnetite adds another interesting function to the drug-loaded carrier because it can be detected by Magnetic Resonance Imaging. In this case, the same nanodevice acts both as a therapeutic tool and an instrument of in vivo detection and imaging - thus combining therapeutics and diagnostics into one single operation, dubbed 'theranostics'. ${ }^{12}$ The device is somewhat similar to a drone: It is remotely guided while its position is followed on a screen. Other detection and imaging compounds include contrast agents, antibodies emitting fluorescent light when binding with their target receptor, or DNA probes activating a fluorophore when hybridizing with their complementary strand (Tiwari et al. 2011). Nanoparticles with embedded iron oxide lining up in a chain and changing direction under the influence of a magnet provide the most suggestive image of a nanorobot. Florence Gazeau, from Université Paris-Diderot, explains: 'The remote control by the application of forces works like a robot: It is the mechanical manipulation of a biological

\footnotetext{
${ }^{12}$ Originally coined to refer to a treatment platform combining a diagnostic test setup with a therapy based on the evolution of the test results (Warner, 2004), theranostic nanomedicine is now defined as 'an integrated nanotherapeutic system which can diagnose, deliver targeted therapy and monitor the response to therapy' (Sumer and Gao, 2008, p. 137).
} 
object' (Gazeau, 2011). ${ }^{13}$

The third operation - the release of the drug on the targeted site-can be triggered either from inside by controlling the stability and degradation time-lapse of the capsule, or from outside by various stimuli-response devices. All the unique properties of the nanoscale can be exploited. For instance, pH-sensitive liposomes and nanoparticules such as chitosan will disassemble before a tumour in an acidic environment; or a carrier made of a thermo-sensitive polymer will become porous by application of hyperthermia on the target and will then release its load; a polymer-coated gold nanoparticle will do the same when irradiated under near-infrared pulsed light, which penetrates deeply into the tissue and causes gold liquefaction (Shakeri-Zadehl et al. 2010, Choi et al. 2011); an iron nanoparticle will overheat and cause cancer cell's necrosis when subjected to a magnetic field. In the latter case the nanoparticle becomes the drug: Drug and device merge. ${ }^{14}$

Each unit operation-loading, addressing, releasing - involved in targeted drug delivery is assigned to a specific device. The combination of these devices in a nanoparticle is often called a nanomedicine 'platform' because of the device's multi-tasking performance: imaging (optical, ultrasound or magnetic resonance detection), targeting agents (peptides, antibodies...), therapeutic tools (chemotherapy, hyperthermia...), and stimuli-responsive agents that activate those functions (Fig. 4).
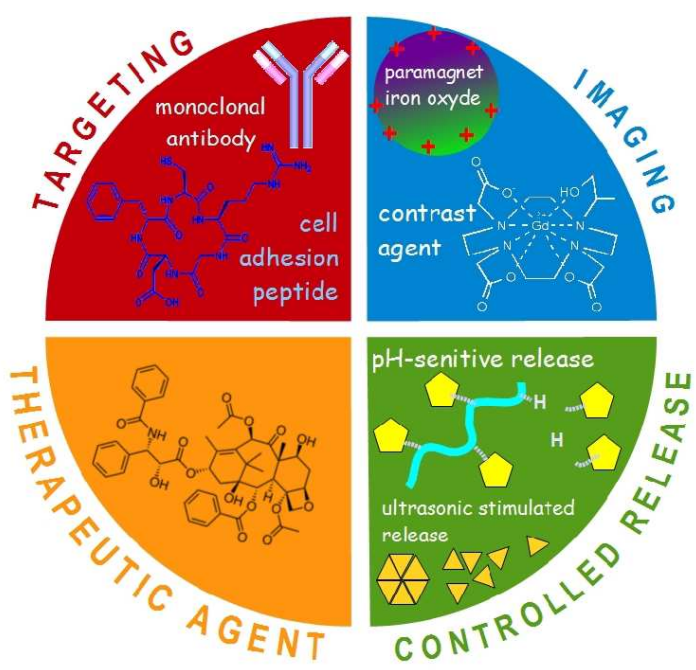

Fig. 4. A nanomedicine platform: an assembly of specific functions (S. Loeve, original picture).

\footnotetext{
${ }^{13}$ Here, 'robot' clearly means an enslaved machine-tool, not an independent automaton. This is not surprising, since, as Nerlich argues $(2005 ; 2008)$, the images of nanobots cleaning fats in blood vessels are recycling the older visual archetypes of shrunk humans travelling through the body, as shown in the movie The Fantastic Voyage. Nanomedicine's imaginary has replaced shrunk surgeons and their tools with miniaturized robots. In turn, the focus has shifted "from the "extraordinary" (voyages) to the "ordinary" (medicine), thereby contributing to the normalisation of nanomedicine and its integration into normal biomilitaristic medical discourse' (Nerlich, 2012). The metaphor of the nanorobot has had to be 'militarized' to move from pure science fiction to something real, serious, and valued by our society.

${ }^{14}$ A striking example of fusion between drug and device is the NanoXray ${ }^{\mathrm{TM}}$ developed by the French start-up Nanobiotix (http://www.youtube.com/watch?v=kxSX6YJTS2I), in which the nanoparticles amplify the physical mode of action of radiotherapy. NanoXray ${ }^{\mathrm{TM}}$ is like a nanoscale extension of the radiotherapy setup internalized in the patient's body to relay and locally amplify its effect. This conflation is also visible in the normative framework of regulation under which the development of NanoXray ${ }^{\mathrm{TM}}$ is placed: under the category 'drug' by the US FDA and under the category 'medical devices' by the French AFSSAPS. This later regime of regulation would, if not accelerate, at least facilitate NanoXray ${ }^{\mathrm{TM}}$ 's entrance in the market by bypassing the ever-expanding 'valley of death' of pharmaceutical development. As a venture capitalist investing in the start-up put it on one of the Nanobiotix's site podcasts, 'I believe we are getting a biotech care company potential with a medical device time-to-market' (http://www.nanobiotix.com/about-us/).
} 
The resulting system is like a 'mille-feuilles' of disciplines comprising of various layers: synthetic chemistry, physics, biochemistry or molecular biology (figure 5). Like most nanoengineering projects the design of nanocapsules requires the convergence of various disciplines at the nanoscale. To a certain extent the nanocarriers are crafted like 'materials by design', they are then functionalized for performing specific tasks.

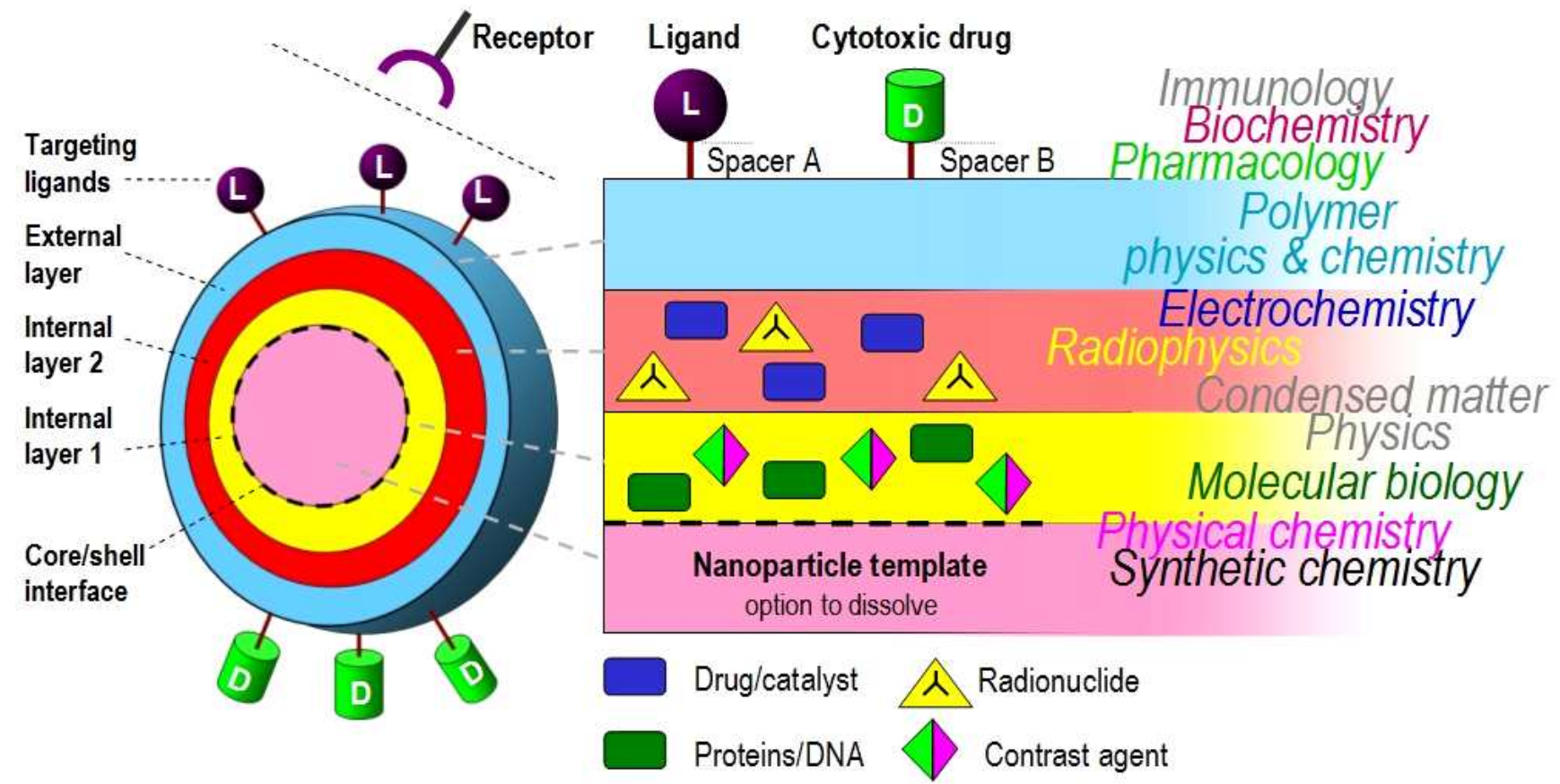

Fig. 5. Layered structure of a multifunctional nanoparticles: A 'mille-feuilles' of disciplines. (S. Loeve, original picture).

It should be clear by now that the resulting approach to therapeutics belongs neither to the Galenic culture of pharmacology nor to its Paracelsian rival. In opposition to the Paracelsian approach, the chemical agent is by no means the unique active principle of the medicine. It is part of a larger technological system combining various functions that all cooperate to the therapeutic action. Conversely, the Galenic formulation becomes so functionalized at the nanoscale that it is no longer possible to draw a clear boundary between the excipients and the active principle (Loeve and Normand, 2011). The formulation is an integral part of the therapeutic system. ${ }^{15}$ Targeted drug delivery systems do not fit in the traditional categories of pharmacological culture and knowledge. They instantiate a technoscientific approach dominated by an abstract engineer's view ${ }^{16}$. Even the performances that are expected from them are formulated in the language of technology assessment (cost/benefit analysis). Each of the functions added to the nanoplatform should increase the ratio of benefits versus costs and be assessed under this model (Cheng et al. 2012).

\footnotetext{
${ }^{15}$ The nanocarriers obtained by 'squalenization' by Couvreur and his team instantiates the identification of the drug with its Galenic formulation. Squalene, a biological organic compound, can chemically bind with the anticancer drug gemcitabin, thus forming a new molecular entity, gemcitabine-squalene, which in turn selfassembles into nanoparticles in water (Phili et al. 2010).

${ }^{16}$ On the difference between abstract and concrete engineering views in nanotechnology see Bensaude-Vincent and Guchet (2007, pp. 79-82).
} 


\section{From a model of efficiency to therapeutic efficacy}

The missile metaphor is attractive because of the translation of a therapeutic project into an engineering problem with clear end (cure cancer) and means (nanocarriers for the transport and stimuli for the release of the medicine). However, is the ballistic metaphor sufficient, is it even necessary? What kind of model is required to combine technological efficiency with therapeutic efficacy? ${ }^{17}$

First of all, if the warfare metaphor is to be maintained, it requires at least more than performing the sequence of unit operations: loading, addressing, releasing. To successfully deliver the right dose in the right place at the right time in the complex environment of a living organism requires at least 'smart weapons' with multifunctional parts. Consider the first unit, the capsule. It has to be designed both as a vehicle and as a container for transporting the active principle. While the nano-size facilitates the circulation through the blood vessels and allows intravenous injections (usually the most dangerous drug administration route for the risk of embolism), for containing the optimal dose of active principle, the nanocapsule presents the inconvenience of a low volume for drug loading. Designing the capsule implies a trade-off between size and dosing. For a successful therapeutics, the designer has to find out the optimal trade-offs afforded by the nanoscale, with regard to the kind of effect s/he chooses to prioritize.

In addition, the capsule does not only carry a 'payload', it also protects the biological milieus from the virulence of the active principle. Targeted drug delivery really took off when doxorubicin has been encapsulated in biodegradable polyalkylcyanoacrylate nanoparticles (Couvreur et al., 1982), lessening the drug's notorious and often prohibitive cardiac toxicity. The container secures the containment of a dangerous material. Its protection is also crucial for expanding the spectrum of potential drugs to biological substances. So far peptides, proteins, nucleic acids have been considered as undeliverable because they are rapidly cleared and degraded in the biological milieu. The still uncertain future of gene therapy will thus depend on the ability to protect the fragile drug through its journey. Whether the therapeutic principle is a highly toxic substance that needs to be isolated from the vulnerable milieu or a fragile degradable biological material that needs a protective container, in both cases, the carrier affords care.

Second, achieving a successful therapy is not simply a matter of guiding a projectile toward a target with the highest precision and optimal trajectory. The designer of the 'smart bomb' has to ensure the stability of the vehicle in the messy biological milieu for increasing its residence time in blood vessels. This challenge requires astute tricks to deal with obstacles occurring at each step. The first obstacle is the opsonisation of the carrier (the marking of a foreign body alerting the defences of the host organism that this exogenous element has to be cleared out from the blood vessels). How to negotiate with this self-defence of the host organism? To face this obstacle the 'magic bullet' had to be disguised or coated. The socalled 'second-generation nanovectors' (Couvreur and Vauthier 2006) are grafted with a sort of hair on the surface of their capsule to make them invisible to the macrophages along their trajectory. Made of a polymer-most often polyethylene glycol (PEG), because it is FDA approved, cheap and biodegradable - the coating creates a cloud of hydrophilic chains, which repels for a time the plasma proteins that mark the non-self. This process named pegylation protects the carrier from disintegration by the immune system, thus enabling its circulation in

\footnotetext{
${ }^{17}$ Efficacy is generally defined as the ability to bring about a desired effect, whereas efficiency measures the ratio of beneficial output (e.g.: useful fork, economic profit) versus (the amount of means/resources) involved (time, energy, effort, costs...). Therapeutic efficacy is the main concern in the development process (where it becomes the most important criterion).
} 
the blood for a much longer period of time. The pegylated particles have a circulating half-life of 45 hours versus a few hours for conventional liposomes.

It is thus clear that the missile metaphor is over-simplistic and not sufficient to achieve therapeutic efficacy. More importantly, this metaphor conveys the misleading image of a kind of navigation system. Unlike a homing missile, the nanovector is not heading straight from the injection site to the target. ${ }^{18}$ It has a random and hazardous journey through the blood vessels until it meets its target and binds to it. ${ }^{19}$

Finally, the image of a weapon hitting a target is not even appropriate to describe the release of the drug. One major challenge is that along its journey through the blood vessel, the decorated carrier is modified by the milieu and even redecorated by it, for instance by dragging a variety of proteins forming what toxicologists name the 'protein corona'. The proteins in the serum form a protective shield, which alters the targeting capabilities of the device (Gaspar, 2013). What the tumour cells 'sees' is not the expected keys that fit in their locks. They 'see' a different and unreadable message (Gazeau, 2011). Whereas an unambiguous lock-and-key response is expected from the target, the target actually affords a unique viewpoint on the nanoparticles, opening unexpected perspectives over unforeseen interactions.

Thus the target is by no means a passive site of impact. Rather it is a new milieu reconfiguring the particle's identity. One major challenge for the success of drug delivery devices is therefore to continuously pay attention to the interactions between the technological device and the milieu.

The description of the nanoplatform as an assemblage of independent functionalities that can be activated by internal or external stimuli is somewhat misleading. It does not take into account the synergistic or antagonistic effects between the artifact and the milieu, which may alter the devices' functions and effects. The image of a carrier moving straight to hit a specific target is only an abstract model that may be appropriate to conduct laboratory experiments. While in vitro tests are indispensable for obvious epistemic and ethical reasons, they tend to generate illusions of control and efficiency. They may become counter-productive if they conceal the problems posed by the complex and stochastic behaviour of the biological milieu. It is thus clear that a strict Paracelsian chemical approach to drug delivery is doomed to fail in nanomedicine.

To improve the current strategies of drug delivery with nanocapsules, is it possible to bridge the gap between in vitro and in vivo performances by integrating the milieu as a third player in the game? While the problem is generally framed in terms of targeting the drugloaded nanovehicle with increased control precision, more efficient and more robust devices relying on the actions and reactions of the cells are designed. Similar to those were the socalled 'first-generation' and 'second-generation' nanovectors. For instance, the 'secondgeneration' nanovectors capitalize on a stratagem developed by the tumour to capture a part of the blood flow. Whereas in healthy blood vessels endothelial cells are bound together by tight junctions, preventing any large particle in the blood from leaking out, in tumours or inflamed tissues, blood vessels do not have the same sealing ability and are consequently more permeable. This increased permeability known as Enhanced Permeability and Retention

\footnotetext{
${ }^{18}$ To be sure, military missiles sometimes release munitions without homing devices, at random, in the hope that enemy targets will be affected by statistics. But they don't have the glamour of surgical strikes.

${ }^{19}$ Even when the drug carrier is equipped with specific antibodies, peptides or ligands, these so-called 'homing devices' do not point only to a target receptor, but also sometimes to a relay receptor enabling the nanovector to cross a biological barrier. For instance, when decorated with the specific antibody of the transferrin receptor, chitosan nanospheres can cross the blood-brain barrier for delivering biologically peptides to the brain (Karatas et al., 2009). In this case, a temporary alliance is contracted with a smuggler afforded by a particular biological milieu.
} 
effect (EPR) ${ }^{20}$ of the tumour capillaries allows liposomes or nanoparticles to slowly permeate the tumour sites (Fig. 6). This 'non-specific targeting' (Fig.3) enables pegylated liposomes to reach tumours sites to deliver drugs while making chemotherapeutic drugs less toxic for healthy tissues. The doxorubicin-loaded liposomes Doxil@ with their size of about $100 \mathrm{~nm}$ allow administrating a higher dose of doxorubicin while providing the patients with a better quality of life (no more nausea, vomiting or hair loss), although new side effects are also experienced $^{21}$. Doxil@ totals almost $\$ 600$ million in annual sales around the world and will soon lose its patent protection.

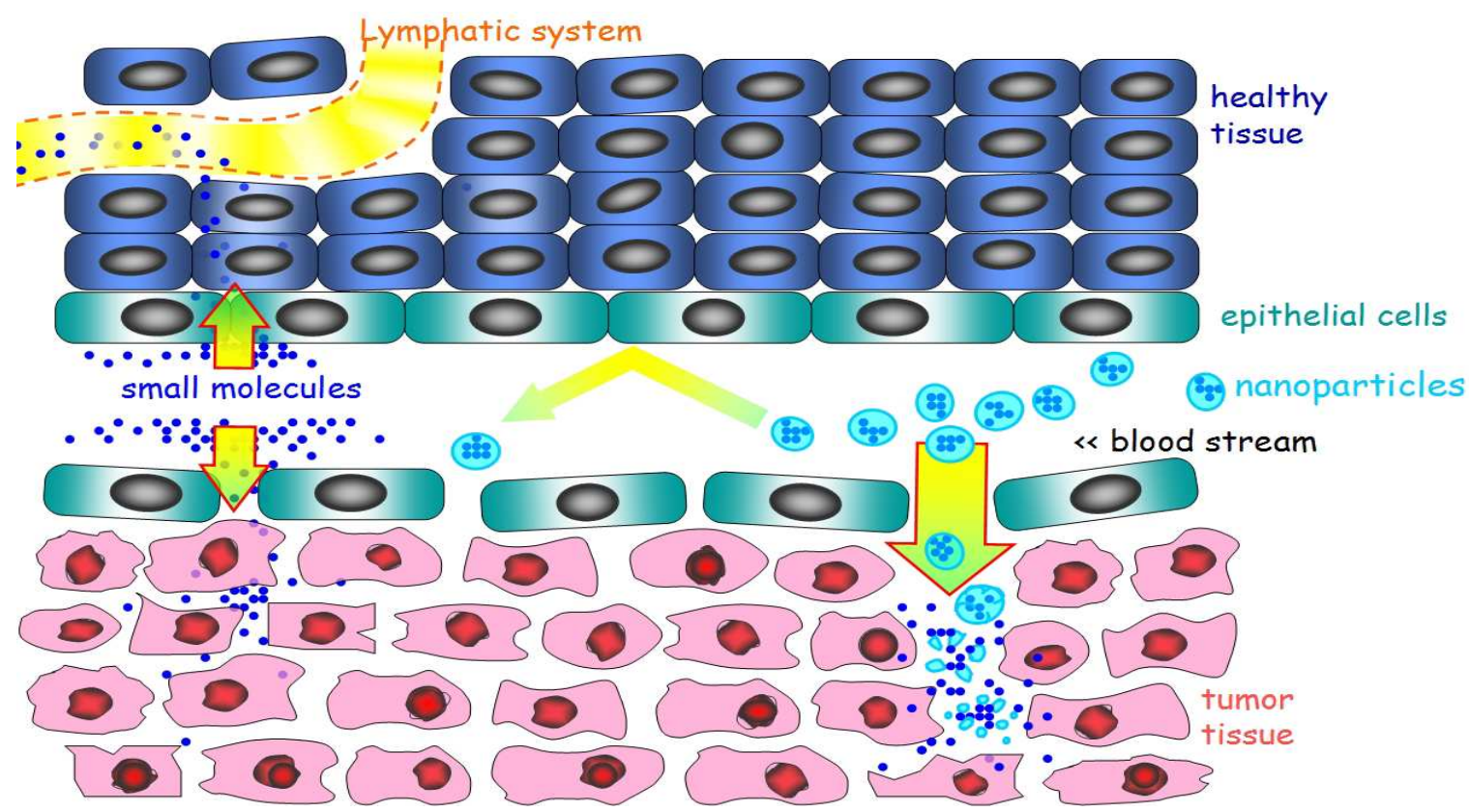

Fig. 6. Addressing tumour tissue through Enhanced Permeability and Retention effect. (S. Loeve, original picture).

New strategies for drug delivery are being envisioned that take into account the complex and dynamic nature of the biological milieu. In particular the modifications induced by the pathology and the treatment in the target at different space and time scales have to be systematically investigated. The tumor microenvironment is characterized by a high structural heterogeneity, multicellular composition, dense extracellular matrix, non-uniform leaky vasculature, continuously evolving interstitial pressure and solid stress, hypoxia and involvement of immune cells (Jain and Stylianopoulos 2010; Perrault et al., 2009). Multistep strategies are being envisioned including a first step to prepare the milieu (normalization of tumor vasculature or of the tumor matrix) and a second step to facilitate drug delivery to the cellular or intracellular target (Wong et al., 2011; Chauhan et al., 2012; Sano et al., 2013). Designing nanoparticles that respond to properties of the tumor microenvironment (for

\footnotetext{
${ }^{20}$ Enhanced Permeability and Retention is the effect of inflammation, which induces the arrival of macrophages and the release of cytokines increasing the permeability of vessels.

${ }^{21}$ This is the case of the palmar-plantar erythrodysesthesia or 'hand-foot syndrome'. Hands and feet are usually subjected to mechanical pressure and friction, which causes instantaneous dilatation of the endothelial tissue of blood vessels which, similarly to the EPR effect. Yet this allows the nanocarriers to locally cross the endothelial wall of healthy tissues. The areas affected become red, dry, peel, numb or painful, with possible necrosis. This unwanted leakage of the nanocarrier can be attenuated by modifying some everyday activities (avoiding wearing tight clothes, using tools, jogging, taking hot showers or being exposed to strong sunlight). But for very sensitive patients such an adverse effect unfortunately limits the maximal safe Doxil® dose that can be administrated as compared with doxorubicin in the same treatment regime.
} 
example low $\mathrm{pH}$ and partial oxygen pressure) is a major trend in the field of cardiovascular diseases. Targeted drug delivery could also be 'pathology-inspired', that is, achieved through endogenous disease-specific mechanical stimuli. ${ }^{22}$ Here again the interactions of nanocarriers with the milieu, and more specifically with the diseased area, triggers opportunities of therapeutic activation. Such stratagems engaging with the milieu as a partner promise to be more robust and widely applicable than the simple molecular recognition initiated with the model of magic bullet. 'Intelligent design' (Couvreur and Vauthier, 2006) of drug delivery could be based on a better understanding of interaction mechanisms between the biological milieu and foreign bodies so as to benefit from them.

The efficiency and efficacy of the military strategy of targeting and shooting are thus questionable. Even when it is extended beyond the realm of ballistics to encompass smart and fine-tuned devices performing various functions, the missile metaphor is not fully adequate. Twelve years of intensive research did not bring about the promised results. The expected economic benefits are so disappointing that some experts recommend reconsidering the entire technology in close interactions with users and regulatory agencies (Te Kulve and Rip, 2012).

It is now clear that the exclusive focus on the nanoparticle (the vehicle) conceals many complex phenomena associated with transport through a living body (Kwon et al., 2012). It reduces the spectrum of possibilities by excluding other potential perspectives. While the image of a missile provides insights, it also generates new forms of ignorance precisely because of its evident simplicity. In particular the offensive rhetoric undermines a subtle finetuning between a variety of mechanisms of protection or even of care. First, the biological tissues are protected from the drug's toxicity thanks to the container, which is in turn protected from the body's defences by the coating. As a matter of care, targeted drug delivery requires a sense of tact and diplomacy. The so-called 'missile' has to be also a 'secret agent' in order to infiltrate into a series of biological milieus and manipulate the interactions between various protagonists. Like the Trojan horse, the nanocapsules conceal their operation by adopting the codes of the infiltrated milieu. The so-called 'missile' has to negotiate access like a good diplomat. Instead of subjecting all obstacles along its path, it has to establish temporary alliances with various smugglers. Nanovectors require the tricks of a wizard and the special talent of kaïros. This persona of Ancient Greek mythology, the son of Athena and grand-son of Zeus and Metis, is good at seizing opportunities. He epitomizes the art of making decision in the right place and at the right moment. This art consists in seizing what the situation affords for performing the next step in an action.

\section{Towards an oïkological approach}

Since the missile metaphor is neither sufficient nor necessary to account for all the spectrum of astute stratagems required to secure therapeutic efficacy, it seems relevant to open the register of linguistic practices to alternative metaphors. It is especially important because, as Bjorn Hofmann convincingly argued (2001), technology plays a leading role in framing medical knowledge. It contributes to shape our concept of disease, our vision of medical intervention on the human body and, last but not least, our vision of the body. The ballistic metaphors rely on an abstract view of the body as a blank geometrical space through which a vector is moving towards a target. By contrast, the emphasis on the interaction with the biological milieu conveys the view of the body as a complex and heterogeneous environment. It consequently brings to mind a quite different metaphoric framework.

We suggest that drug delivery research could be advantageously framed in terms of domestic economy or 'oïkology' (from oïkos, 'house', the common root for both ecology and

\footnotetext{
${ }^{22}$ For this purpose, lentil-shaped liposomes were designed to release their content only under the high shear stress found in constricted blood vessels (Korin et al.; 2012 Holme et al., 2012).
} 
economy). The concern with the management of doses and transportation, which prevails in the still fashionable military metaphors, would be supplemented by an art du ménagement (care). From this perspective, the designer would have to take care of the interactions between technological devices and the milieu where they operate. In the oïkological model, the human body is conceived as an oikos populated with a variety of habitants. It is a crowded and uneven terrain, a landscape of ecological niches. In the military framework, drug delivery is a strategic game opposing two players - the drug and the target-, whereas in the oïkological framework the game involves a variety of players capable of assuming various roles. Each of them requires care, protection and tact for the process to work. Their local interactions have to be orchestrated from place to place as the drug pursues its journey inside the body. In the ballistic vision, the therapeutic devices are positioned against the barriers that stand between the healthy organism and the pathogen target. In the oïkological vision, recovering health is to inhabit and tame the sick body, which is actually a plausible view of cancer (Merlo et al., 2006; Boenink, 2009; Gatemby, 2009; Gatemby et al., 2009a; 2009b; Caroll, 2011).

To develop an alternative oïkological metaphoric framework we have to clarify the mode of existence of nanomedical devices for targeted therapy. For this purpose, the conceptual distinction between dispositions and affordances may be helpful. It is often claimed that nanotechnology enables to control and monitor the delivery process (Park, 2007, Gabizon, 2001). The objects designed for drug targeting are usually named 'nano-devices' - a very well chosen term, because 'devices' (in French 'dispositifs') precisely can activate dispositions. To put it in more philosophical terms, nanoplatforms rely on dispositional properties when they are designed as missiles. ${ }^{23}$ In the case of nanoplatforms, the dispositions are the unique physicochemical properties of the nano-scale that can be actualized in a specific 'dispositif'. Targeted drug delivery systems are 'devices' precisely because they activate dispositions. By contrast the term 'affordance' refers to the intrinsic capability of an object as well as to the gift or the service that the said object is able to deliver to its user (for instance thick ice affords skating). ${ }^{24}$ Affordances combine generic material dispositions and specific intentions and purposes. Whereas a disposition is a latent property inherent to a substance or based on the laws of nature, affordance is relational and definitely not substantial. Unlike dispositions, affordances are not latent potentials waiting for being activated; they do not pre-exist their actualization. Affordances are created within and by the coupling of an agent and a material system; they are rendered possible by this encounter. Affordances thus blur the potential/actual dichotomy, as well as the subject/object divide. Affordances are objective instances because they are offered by the environment and subjective because the offer is generated with regard to a perceptive agent. Affordances are hybrid entities-part constructs, part nature-whose causal powers cannot be disentangled.

For instance, in today research programs on drug delivery, the process of opsonisation of the carrier is treated as an obstacle to be overcome, whereas in an 'oïkologic' framework, it would be treated as an affordance of the milieu. All the responses of the biological milieu to the introduction of a nanocapsule could serve as models of design. As pointed out by Richard Jones, nanotechnology could learn a lot from nature by investigating in vivo molecular

\footnotetext{
${ }^{23}$ To attribute a dispositional property to a thing amounts to saying that if certain conditions are obtained, then that thing will behave in a specific manner or bring about a specific effect. For instance 'a negatively charged particle is one of which it is true that, if brought into proximity to another negatively charged particle, it will experience a force of repulsion' (Harré 2001, p. 97).

${ }^{24}$ In Gibson's ecological theory of perception, affordances are the possibilities of action that are offered to an agent by an environment (Gibson, 1979). The concept has also been taken over in design theory, to express how objects invite and constrain their users by offering 'cues for action' (Norman, 1990; DiMaggio, 1997). It has recently been used by Rom Harré to develop a pragmatic account of scientific experimentation which consists of 'apparatuses/world complexes' affordances (Harré, 2003). Apparatuses/world complexes afford things, processes and activities that cannot be constituted nor sustained independently from technical projects.
} 
processes and try to capitalize on its findings - a major feature of what Jones dubs 'soft engineering': 'The advantage of soft engineering is that it does not treat the special features of the nanoworld as problems to be overcome, instead it exploits them and indeed relies on them to work at all' (Jones, 2004, p. 127).

Changing obstacles into positive principles of work is exactly what the French philosopher Gilbert Simondon recommended for the design of 'concrete' machines as opposed to 'abstract' ones (Simondon, 1958). For Simondon, a 'concrete engineer' is one who pays attention to, and takes advantage of, the environment affordances. Unlike the abstract engineer, a concrete engineer does not aim to improve the machine's efficiency first, to introduce it ultimately into its work environment. But instead, by imagining the machine in its environment and 'playing the milieu', the concrete engineer anticipates the effects of its operational effects on the environment, and then tries to integrate them into the machine's working principles. A concrete nanomachine would work precisely because of - and not despite-its association with its environment, which becomes the machine's 'associated milieu' and not an external parameter that engineers have to take into account after designing artefacts. Simondon's 'associated milieu' is not something to which a standard, ready-made machine will have to be adjusted. It is an intrinsic aspect of the design of the machine. It means that each ingredient of the complex system is envisaged as a relational entity defined by its interactions with the environment rather than a physicochemical entity with a stable identity (table 1).

Table 1 : Summary of the contrasts between the two metaphorical frameworks

\begin{tabular}{|c|c|c|}
\hline Representations of & Warfare Model & Ö̈kological model \\
\hline Body & $\begin{array}{l}\text { Field of operations visualized on a } \\
\text { radar screen. A passive, amorphous } \\
\text { transparent and homogeneous } \\
\text { space to go through to reach a } \\
\text { target }\end{array}$ & $\begin{array}{l}\text { Multiple ecological niches } \\
\text { interrelated by various modes of } \\
\text { containement and interaction (e.g. } \\
\text { selective membrane). An opaque, } \\
\text { uneven and over-crowded milieu }\end{array}$ \\
\hline Disease & A local entity to be eradicated & A relational singularity to be tamed \\
\hline Health & $\begin{array}{l}\text { State of well-being resulting from } \\
\text { the absence, or the destruction, of } \\
\text { disease }\end{array}$ & $\begin{array}{l}\text { Inhabiting the body again. } \\
\text { Learning process of adaptation to } \\
\text { the new condition created by the } \\
\text { disease (no return to the biological } \\
\text { innocence) }\end{array}$ \\
\hline Therapeutic device & $\begin{array}{l}\text { Missile targeting a pathogenic } \\
\text { entity }\end{array}$ & $\begin{array}{l}\text { Diplomat negotiating a } \\
\text { compromise while taking care of } \\
\text { her homeland }\end{array}$ \\
\hline Therapeutic act & $\begin{array}{l}\text { Strategic game between two actors: } \\
\text { the drug and the target }\end{array}$ & $\begin{array}{l}\text { 'Art du ménagement'. Tactic game } \\
\text { involving multiple actors to be } \\
\text { interrelated and cared for at each } \\
\text { step of the drug's journey through } \\
\text { the body }\end{array}$ \\
\hline Nano-object & $\begin{array}{l}\text { Transparent functionalized entity } \\
\text { under control because it is the } \\
\text { result of human design and } \\
\text { engineering }\end{array}$ & $\begin{array}{l}\text { Relational entity defined by its } \\
\text { interactions (e.g. protein corona) }\end{array}$ \\
\hline
\end{tabular}

\section{Conclusion}


Brigitte Nerlich has suggested that Gibson's notion of affordance could help conceptualize metaphors themselves in ecological terms. "An ecological theory of metaphor would study the "structural coupling" between a metaphor and the environment (...). Over and above its intrinsic semantics [the metaphor] therefore has a "pragmatic", dynamic, action-oriented face' (Nerlich, 2003, p. 136). If we assume, with Nerlich, that metaphors do have affordances, depending on their environment or 'niches', then we have to have to acknowledge the 'magic affordances' of the 'magic bullet' and the 'therapeutic missile'.

First, in the current context of crisis in pharmaceutical industry the missile metaphor affords public confidence. The underlying values of control and precision are more socially acceptable than the view of a nanovectors seizing opportunities in the course of a random journey through the body. Missiles and nanorobots are more reassuring for patients and more convincing for investors and industrial companies.

Second, the image of a smart vector penetrating into a passive cell is clearly bound up with masculinity and reflects the gender bias that Fox Keller noticed in the accounts of molecular biology (1992). The preference for accounts relying on mechanisms of a stunning simplicity over others emphasizing complexity is a marked distinction of biotechnology and nanotechnology and can be related to the prevailing male vision of how the body works.

Third, the over-emphasis on the dispositions of nanoparticles is also important for patenting purposes. Despite significant extensions over the past decade, the patent system still relies on claims of invention, and thus on artefacts. Since drug delivery research is mainly patent-oriented, it must avoid putting the emphasis on processes already performed by nature. Hence the idea that drug delivery research in comparison with other fields of nanotechnology only contains a small proportion of biomimetic stances-mostly limited to the 'Trojan horse' stratagems exemplified by viruses and phage.

Despite its advantages, the missile metaphor does not do full justice to the complexity of the issue. Addressing drugs to a specific site and releasing the right dose in the right place at the right moment in the complex environment of a living body requires more than a magic bullet. In addition to the various disciplines that converge in all engineering project, nanomedicine requires the engagement of the biological milieu as a partner. Therefore, the Paracelsian model underlying the ballistic metaphor which may be adequate for in vitro demonstrations of efficiency must be completed by a genuine Galenic model of a complex and responsive milieu. The metaphor of the magic bullet has a limited heuristic power and brings about disappointing results. Ballistic is not the relevant technological model because it provides a distorted and biased view of the operations to be performed by nanomedical devices. Since they have to negotiate with the biological milieu and take advantage of what it affords by turning obstacles into facilitators, an alternative metaphoric framework is needed. It thus comes as no surprise that a number of recent research trends in targeted drug delivery focus increasingly on the milieu thus exploring the potentials of the 'oïkological' approach. (Loeve et al. 2013)

Although the broad question of the definition of nanoparticles remains far beyond the scope of this paper, it is not extravagant to suggest that the oïkological metaphor could be extended to other fields of nanotechnology, where it would afford new perspectives. If the relations between nanoparticles and their environment were no longer treated as side effects and rather as integral parts of their definition and characterization, research priorities could be dramatically changed. In today nano-initiatives nanotoxicological studies of interactions between nanoparticles and biological tissues or interactions with the environment are often viewed as a necessary detour for the safe and successful mass diffusion of nanotechnological products whereas they could become the hard core of the research field. This is just a tentative scenario of what might happen if nanoresearch were to focus on the interactions of nanoobjects with their environment. 


\section{Funding Sources}

The research for this paper has been conducted by the authors with the help of ANR-project Nano-2E ANR-09-NANO-001-02.

\section{Acknowledgments}

We are grateful to Patrick Couvreur, Florence Gazeau, Ania Servant, Cyril Bussy, and Brigitte Nerlich-

\section{References}

Austin, J. L. (1962). How to Do Things with Words. (Oxford: Clarendon Press).

Annas, G. (1995). Reframing the debate on health care reform by replacing our metaphors. New England Journal of Medicine, 332, 744-747.

Arrigo, B. A. (1999). Martial metaphors and medical Justice: Implications for law, crime, and deviance. Journal of Political and Military Sociology, 27, 307-322.

Bawa, R. (2008). Nanoparticle-based Therapeutics in Humans: A Survey. Nanotechnology Law \& Business, 5, $135-155$

Bensaude-Vincent, B., Guchet, X. (2007). Nanomachine : One Word for Three Different Paradigms. Technè, 11, 71-89.

Bhattacharya, S. (2003, November 4). Gold "nano-bullets" shoot down tumours. New Scientist. Retrieved August 20, 2012, from http://www.newscientist.com/article/dn4341-gold-nanobullets-shoot-downtumours.html.

Boenink M., (2009). Tensions and Opportunities in Convergence: Shifting Concepts of Disease in Emerging Molecular Medicine, Nanoethics, 3, 243-255.

Caroll, S. P. (2011). Conciliation biology: the eco-evolutionary management of permanently invaded biotic systems. Evolutionary Applications, 4, 184-199.

Chauhan, V.P., Stylianopoulos, T., Martin, J.D., Popovic, Z., Chen, O., Kamoun, W.S., Bawendi, M.G., Fukumura, D., Jain, R.K. (2012). Normalization of tumour blood vessels improves the delivery of nanomedicines in a size-dependent manner. Nature Nanotechnology, 7, 383-388.

Chess, R. (1998). Economics of drug delivery. Pharmaceutical Research, 15, 172-174.

Cheng Z., Zaki A. A., Hui J. Z., Muzykantov V. R., Tsourkas A. (2012). Multifunctional nanoparticles: Cost versus Benefit of adding targeting and imaging capabilities. Science, 338, 903-910.

Choi, C. (2009, March 3). Magic Nano-Bullets: Advances in nanotechnology could make drug delivery far more accurate and effective. Scientific American/World View. Retrieved August 20, 2012 from http://www.saworldview.com/article/magic-nano-bullets.

Choi, W.I., Kim, J.Y., Kang, C., Byeon, C.C., Kim, Y.H., Tae, G. (2011). Tumor regression in vivo by photothermal therapy based on gold-nanorod-loaded, functional nanocarriers. ACS Nano, 5, 1995-2003.

Couvreur, P., Tulkens, P., Roland, M., Trouet, A., Speiser, P. (1977). Nanocapsules: A New Type of Lysosomotropic Carrier. FEBS Letters, 84, 323-326.

Couvreur, P., Kante, B., Grislain, L., Roland, M., Speiser, P. (1982). Toxicity of polyalkylcyanoacrylate nanoparticles II: Doxorubicin-loaded nanoparticles. Journal of Pharmaceutical Sciences, 71, 1520-6017.

Couvreur, P., Vauthier C. (2006). Nanotechnology. Intelligent design to treat complex disease. Pharmaceutical Research, 23, 1417-1450.

Couvreur, P. (2009, October 5) Super Vector !, Revue pour l'histoire du CNRS, 24. Retrieved February 10, 2012 from http://histoire-cnrs.revues.org/9061.

Couvreur, P. (2010) Interview by Xavier Guchet, Sacha Loeve \& Nicolas Sauret, Faculté de pharmacie de Chatenay-Malabry, 30 November 2010.

Crawford, L. M. (2004, April 3) Remarks by Lester M. Crawford, D.V.M., Ph.D., Acting Commissioner of the FDA, before PhRMA Annual Meeting. Retrieved February 10, 2012, from http://www.fda.gov/NewsEvents/Speeches/ ucm053576.htm.

De Angelis, C., Drazen, J. M., Frizelle, F. A., Haug, C., Hoey, J., Horton, R., Kotzin, S., Laine, C., Marusic, A., Overbeke, J. P. M., Schroeder, T. V., Sox, H. C., Van Der Weyden, M. B. (2004). Clinical trial registration: 
a statement from the International Committee of Medical Journal Editors. Journal of the American Medical Association, 1671, 137-141.

Debus, A. G. (1991). The French Paracelsians. The Chemical Challenge to the Medical and Scientific Tradition in Early Modern France. (Cambridge: Cambridge University Press).

Debus, A. G. (1993). Paracelsus and the Medical Revolution of the Renaissance; A 500th Anniversary Celebration. (In A. G. Debus (Ed.), Paracelsus, Five Hundred Years; Three American Exhibits (p. 3). Washington, DC: National Library of Medicine).

DiMaggio, P. (1997). Culture and Cognition. Annual Review of Sociology, 23, 263-288.

DiMasi, J. A., Hansen, R. W., Grabowski H. G. (2003). The price of innovation: new estimates of drug development cost. Journal of Health Economics, 22, 151-185.

Downing, G. J. (2009). Key aspects of health care on the path to personalized medicine. Translational Research, $154,272-276$.

Drews, J. (2000). Drug Discovery: A Historical Perspective. Science, 287, 1960-1964.

Ehrlich, P. ([1906] 1960). Address delivered at the Dedication of the Georg-Speyer-Haus. (In: F. Himmelweit (Ed.) The collected papers of Paul Ehrlich (p. 53-63). London: Pergamon Press).

Fox Keller, E. (1992). Secrets of Life, Secrets of Death: Essays on Language, Gender and Science. (New York: Routledge).

Fox Keller, E. (1995). Refiguring Life: Metaphors of Twentieth-Century Biology. (New York: Columbia University Press).

Fox Keller, E. (2002). Making Sense of Life: Explaining Biological Development with Models, Metaphors, and Machines. (Harvard: Harvard University Press).

Gabizon, A. A. (2001). Stealth liposomes and tumor targeting: one step further in the quest for the magic bullet. Clinical Cancer Research, 7, 243-54.

Galison, P. (1994). The Ontology of the Enemy: Norbert Wiener and the Cybernetic Vision. Critical Inquiry, 21, 228-266.

Gaspar, R. (2013). Pushed off target with proteins. Nature Nanotechnology, 8, 79-80.

Gatenby R. A. (2009). A change of strategy in the war on cancer. Nature, 459, 508-509.

Gatenby, R. A., Brown, J., Vincent, T. (2009a). Lessons from applied ecology: cancer control using an evolutionary double bind. Cancer Research, 69, 7499-7502.

Gatenby, R. A., Silva, A. S., Gillies, R. J., Frieden, B. R. (2009b). Adaptive therapy. Cancer Research, 69, 48944903.

Gazeau, F. (2011). Interview by B. Bensaude Vincent, Université Paris-Diderot, 29 November 2011.

Gibson, J. J. (1979). The ecological Approach to Visual Perception. (Boston: Houghton Mifflin).

Goldacre, B. (2012). Bad Pharma: How drug companies mislead doctors and harm patients. (London: Fourth Estate).

Harney, J. (2004, April 30). Nano weapons join the fight against cancer - "Nanoshells" and other tools of the ultrasmall realm could improve diagnosis and treatment of tumors. Technology Review, Retrieved May 11, 2012, from http://www.technologyreview.com/news/402690/nano-weapons-join-the-fight-against-cancer.

Harré, R. (2001). Dispositions and Powers. (In W. H. Newton-Smith (Ed.), A Companion to the Philosophy of Science (pp. 97-101). Oxford: Blackwell Companions to Philosophy, Blackwell Publishers).

Harré, R. (2003). The Materiality of instruments in a metaphysics for experiments. (In H. Radder (Ed.), Philosophy of scientific experimentation (pp. 19-38). Pittsburgh, PA: University of Pittsburgh Press).

Henderson, M. (2009, November 5). New attack on cancer with nano-weapon. The Times (London), November 5, p. 3.

Hillaireau, H., Couvreur, P. (2009). Nanocarriers' entry into the cell: relevance to drug delivery. Cellular And Molecular Life Sciences, 66, 2873-2896.

Hoffman, A. S. (2008). The origins and evolution of 'controlled' drug delivery systems. Journal of Controlled Release, 132, 153-163.

Hofmann, B. (2001). The technological invention of disease. Medical Humanities, 27, 10-19.

Holme, N. M., Fedotenko, A. I., Abegg, D., Althaus, J., Babel, L., Favarger, F., Reiter, R., Tanasescu, R., Zaffalon, P.-L., Ziegler, A., Müller, B., Saxer, T., Zumbuehl, A. (2012) Shear-stress sensitive lenticular vesicles for targeted drug delivery Nature Nanotechnology 7, 536-543.

Jain, K. K. (2005). Role of nanobiotechnology in developing personalized medicine for cancer. Technology in Cancer Research and Treatment, 4, 645-50.

Jain, R. K., Stylianopoulos, T. (2010). Delivering nanomedicines to solid tumors, Nature Reviews Clinical Oncology, 11, 653-64.

Jones, R. (2004). Soft Machines. Nanotechnology and life. (Oxford, New-York: Oxford University Press).

Kain, D. (2008, July 7). "Smart Bomb" Nanoparticle Strategy Impact Metastasis. UC San Diego News Center Letter. Retrieved August 10, 2012 from http://ucsdnews.ucsd.edu/newsrel/health/07-07SmartBomb.asp. 
Karatas, H., Aktas, Y., Gursoy-Ozdemir, Y., Bodur, E., Yemisci, M., Caban, S., Vural, A., Pinarbasli, O., Capan, Y., Fernandez-Megia, E., Novoa-Carballal, R., Riguera, R., Andrieux, K., Couvreur, P., Dalkara T. (2009). A Nanomedicine Transports a Peptide Caspase-3 Inhibitor across the Blood-Brain Barrier and Provides Neuroprotection. The Journal of Neuroscience, 29, 13761-13769.

Kopf, H. (1975). Charakterisierung, Anwendung und Eignung der Nanokapsulierung auf Acrylamidbasis, zur Einhüllung niedermolekolarer Arzneistoffe. Dissertation $n^{\circ}$ 5458, ETH Zürich.

Kopf, H., Joshi, R. K., Soliva, M., Speiser, P. (1976). Studium der Mizellpolymerisation in Gegenwart niedermolekularer Arzneistoffe. 1: Herstellung und Isolierung der Nanopartikel, Restmonomerenbestimmung, physikalisch-chemische Daten, Pharmazeutische Industrie, 38, 281-284.

Kopf, H., Joshi, R.K., Soliva, M., Speiser, P. (1977). Studium der Mizellpolymerisation in Gegenwart niedermolekularer Arzneistoffe. 2: Bindungsart von inkorporierten niedermolekularen Modellarzneistoffen an Nanopartikel auf Polyacrylamid-Basis. Restmonomerenbestimmung, physikalisch-chemische Daten, Pharmazeutische Industrie, 39, 993-997.

Korin, N., Kanapathipillai, M., Matthews, B. D., Crescente, M., Brill, A., Mammoto, T., Ghosh, K., Jurek, S., Bencherif, S.A., Bhatta, D., Coskun, A.U., Feldman, C.L., Wagner, D.D., Ingber, D.E. (2012). ShearActivated Nanotherapeutics for Drug Targeting to Obstructed Blood Vessels. Science, 337, 738-742.

Kramer, P. A. (1974). Albumin microspheres as vehicles for achieving specificity in drug delivery. Journal of Pharmaceutical Sciences, 63, 1646-1647.

Kwon, I.K., Lee, S.C., Han, B., Park, K. (2012). Analysis of the current status of targeted drug delivery to tumors. Journal of Controlled Release, 164, 108-114.

Lakoff, G., Johnson, M. (1980). Metaphors we live by. (Chicago: University of Chicago Press).

Loeve, S. \& Normand M. (2011). How to Trust a Molecule? The case of Cyclodextrins Entering the Nanorealm. (In T.B. Zülsdorf, C. Coenen, U. Fiedeler, A. Ferrari, C. Milburn, M. Wienroth (Eds), Quantum Engagements. Social reflections of nanoscience and emerging technologies (pp. 195-217). Heidelberg: IOS Press / AKA Verlag).

Loeve,S., Bensaude Vincent B, Gazeau F. (2013) Nanomedicine metaphors: From War to Care. Emergence of an oecological approach", NanoToday, Available online 9 September 2013, ISSN 1748-0132, http://dx.doi.org/10.1016/j.nantod.2013.08.003. (http://www.sciencedirect.com/science/article/pii/S1748013213000881)

Maasen, S. \& Weingart, P. (2000). Metaphors and the Dynamics of Knowledge. (London: Routledge).

Manish, G. \& Vimukta, S. (2011). Targeted drug delivery system: A Review. Research Journal of Chemical Sciences, 1, 135-138.

Marty, J.J. (1977). The Preparation, Purification, and Properties of Nanoparticles, Dissertation, Victorian College of Pharmacy, Parksville, Australia.

Marty, J.J, Oppenheim, R.C., Speiser, P. (1978.) Nanoparticles - A new colloidal drug delivery system. Pharmaceutica Acta Helvetiae, 53, 17-23.

Merlo, L. M., Pepper, J. W., Reid, B. J., Maley, C. C. (2006). Cancer as an evolutionary and ecological process. Nature Reviews Cancer, 6, 924-935.

Montgomery, S. L. (1991). Codes and combat in biomedical discourse, Science as Culture, 2, 341-391.

Montgomery, S. L. (1996). The scientific voice. (New York: Guilford Press).

Morris, M. C. (2012). Cancer et nanotechnologie. Innovation en diagnostic, vectorisation et thérapeutique. Rayonnement du CNRS, 58, 47-57.

Munos, B. (2009). Lessons for 60 years of pharmaceutical innovation. Nature Reviews: Drug Discovery, 8, 959968.

Nerlich, B. (2003). Tracking the fate of the metaphor 'Silent Spring' in British environmental discourse: Towards an evolutionary ecology of metaphor. Metaphorik.de, 04. Retrieved November 12, 2012 from http://www.metaphorik.de /04/nerlich.htm.

Nerlich, B. (2005, December 15, 2005). From Nautilus to Nanobo(a)ts: The Visual Construction of Nanoscience. AZojono: Journal of Nanotechnology Online. Retrieved January 28, 2012 from http://www.azonano.com/article.aspx?ArticleID=1466.

Nerlich, B. (2008). Powered by Imagination: Nanobots at the Science Photo Library. Science as Culture, 17, 269-292.

Nerlich, B. (2012, April 15, 2012). Biomilitarism and nanomedicine: Evil metaphors for the good of human health? Covalence. Retrieved May 26, 2012, from http://www.elca.org/What-We-Believe/SocialIssues/Faith-Science-and-Technology/Covalence/Features/Biomilitarism-and-nanomedicine.aspx.

Nordmann, A. (2004, November). Smart Bombs against Cancer Cells: Images of Efficiency in NanoMedicine. (Paper presented at the Conference Nanotechnology and Smart Materials for Medical Applications: From Medical Diagnostic to Therapy, Rome, November 29-30). Retrieved Febreuary 16, 2012, from www.nanotec.it/nanomedicine/presentazioni/nordmann.pdf.

Norman, D. A. (1990). The design of everyday things. (New York: Doubleday). 
Observatory NANO (2010). Focus report: Nanotechnology and therapeutic delivery. Retrieved May 11, 2012, from http://www.observatorynano.eu/project/catalogue/2HM.FO/.

Observatory NANO (2012) Final Report. Retrieved May 11, 2012, from http://www.observatorynano.eu/project/document/3733/.

Park, K. (2007). Nanotechnology: What it can do for drug delivery, Journal of Controlled Release, 120, 1-3.

Patel, P. (2007, July 2). New nano weapon against cancer - Gold nanoparticles with branching polymers could attack tumors in multiple ways, Technology Review. Retrieved May 14, 2012, from http://www.technologyreview.com/news/408187/new-nano-weapon-against-cancer/.

Pillai, O., Dhanikula, A. B., Panchagnula, R. (2008). Drug delivery: An Odyssey of 100 years, Current Opinion in Chemical Biology, 5, 439-446.

Pili, B., Bourgaux, C., Amenitsch, H., Keller, G., Lepêtre-Mouelhi, S., Desmaële, D., Couvreur, P., Ollivon, M. (2010). Interaction of a new anticancer prodrug, gemcitabine-squalene, with a model membrane: coupled DSC and XRD study. Biochimica et Biophysica Acta, 1798, 1522-1532.

Perrault, S. D., Walkey, C., Jennings, T., Fischer, H. C., Chan, W. C. W. (2009). Mediating Tumor Targeting Efficiency of Nanoparticles Through Design. Nano Letters, 9, 1909-1915.

Paul, S. M., Mytelka, D. S., Dunwiddie, C. T., Persinger, C. C., Munos B. H., Lindborg, S. R., Schacht A. L. (2010). How to improve R\&D productivity: the pharmaceutical industry's grand challenge. Nature Reviews: Drug Discovery, 9, 203-214.

Perez, A. (2008, February 12). Les nanomédicaments s'attaquent au cancer - Plusieurs projets de recherche français confirment l'intérêt scientifique et le potentiel thérapeutique des nanomédicaments. Les Echos, 20108, 17. Retrieved August 10, 2012, from http://archives.lesechos.fr/archives/2008/LesEchos/20108-78ECH.htm.

Tiwari P.M., Vig, K., Dennis, V.A., Singh, S.R. (2011). Functionalized Gold Nanoparticles and Their Biomedical Applications. Nanomaterials, 1, 31-63.

Rai, M. K., Deshmukh, S. D., Ingle, A. P., Gade A., K. (2012). Silver nanoparticles: the powerful nanoweapon against multidrug-resistant bacteria. Journal of Applied Microbiology, 112, 841-52.

Rasmussen, A. (2005). Préparer, produire, présenter des agents thérapeutiques. Histoires de l'objet médicament. (In C. Bonah, A. Rasmussen (Eds.), Histoire et médicament aux XIXe et XXe siècles (pp. 159188) Paris: Éditions Glyphe).

Rorty R. (1979). Philosophy and the Mirror of Nature. (Princeton, NJ: Princeton University Press).

Rossi, M. A. (2012). Targeting Anti-Epileptic Drug Therapy Without Collateral Damage: Nanocarrier-Based Drug Delivery. Epilepsy Currents, 12, 199-200.

Sano, K., Nakajima, T., Choyke, P.L., Kobayashi H. (2013). Markedly enhanced permeability and retention effects induced by photo-immunotherapy of tumors. ACS Nano, 7, 717-724.

Shakeri-Zadeh1, A., Ali Mansoori, G., Reza Hashemian, A., Eshghi, H., Sazgarnia, A., Reza Montazebadi, A. (2010). Cancerous Cells Targeting and Destruction Using Folate Conjugated Gold Nanoparticles. Dynamic Biochemistry, Process Biotechnology and Molecular Biology, 4, 6-12.

Simondon, G. (1958). Du mode d'existence des objets techniques. ( $2^{\text {nd }}$ edition 1989, Paris: Aubier).

Singer, E. (2009, November 4). Stealthy nanoparticles attack cancer cells: Drugs embedded in special polymers can more effectively shrink tumors. Technology Review, Retrieved May 14, 2012, from http://www.technologyreview.com/business/23855/.

Strebhardt K. \& Ullrich, A. (2008). Timeline: Paul Ehrlich's magic bullet concept: 100 years of progress, Nature Reviews Cancer, 8, 473-480.

Sumer, B. \& Gao, J. (2008). Theranostic nanomedicine for cancer. Nanomedicine, 3, 137-140.

Te Kulve H. \& Rip A. (2013). Societal and economic dimensions of nano-enabled drug delivery. Expert Opinion on Drug Delivery, 10, 611-622.

Swinney D. C., \& Anthony J. (2011). How were new medicines discovered? Nature Reviews: Drug Discovery, 10, 507-519.

Wagner, V., Dullaart, A., Bock, A.-K., Zweck, A. (2006). The emerging nanomedicine landscape. Nature Nanotechnology, 24, 1211-1217.

Warner, S. (2004). Diagnostics plus therapy = theranostics. Scientist, 18, 38-39.

Wong, C., Stylianopoulos, T,. Cui, J., Martin, J., Chauhan, V.P., Jiang, W., Popović, Z., Jain, R.K., Bawendi, M.G., Fukumura, D. (2011). Multistage nanoparticle delivery system for deep penetration into tumor tissue. Proceedings of the National Academy of Sciences, 108, 2426-2431. 